Article

\title{
A 3D Microfluidic Chip for Electrochemical Detection of Hydrolysed Nucleic Bases by a Modified Glassy Carbon Electrode
}

\author{
Jana Vlachova ${ }^{1,2}$, Katerina Tmejova ${ }^{1,2}$, Pavel Kopel ${ }^{1,2}$, Maria Korabik ${ }^{3}$, Jan Zitka ${ }^{1}$, \\ David Hynek ${ }^{1,2}$, Jindrich Kynicky ${ }^{4}$, Vojtech Adam 1,2 and Rene Kizek 1,2,*
}

1 Department of Chemistry and Biochemistry, Faculty of Agronomy, Mendel University in Brno, Zemedelska 1, Brno CZ-613 00, Czech Republic; E-Mails: jaja.vlachova@gmail.com (J.V.); severova@centrum.cz (K.T.); paulko@centrum.cz (P.K.); zitka12@gmail.com (J.Z.); d.hynek@email.cz (D.H.); vojtech.adam@mendelu.cz (V.A.)

2 Central European Institute of Technology, Brno University of Technology, Technicka 3058/10, Brno CZ-616 00, Czech Republic

3 Faculty of Chemistry, University of Wroclaw, 14 Joliot-Curie, Wroclaw PL-50383, Poland; E-Mail: maria.korabik@chem.uni.wroc.pl

4 Karel Englis College, Sujanovo nam. 356/1, Brno CZ-602 00, Czech Republic; E-Mail: jindrak@email.cz

* Author to whom correspondence should be addressed; E-Mail: kizek@sci.muni.cz; Tel.: +420-5-4513-3350; Fax: +420-5-4521-2044.

Academic Editor: Libuse Trnkova

Received: 22 October 2014 / Accepted: 4 January 2015 / Published: 22 January 2015

\begin{abstract}
Modification of carbon materials, especially graphene-based materials, has wide applications in electrochemical detection such as electrochemical lab-on-chip devices. A glassy carbon electrode (GCE) modified with chemically alternated graphene oxide was used as a working electrode (glassy carbon modified by graphene oxide with sulphur containing compounds and Nafion) for detection of nucleobases in hydrolysed samples $\left(\mathrm{HCl} \mathrm{pH}=2.9,100{ }^{\circ} \mathrm{C}, 1 \mathrm{~h}\right.$, neutralization by $\mathrm{NaOH}$ ). It was found out that modification, especially with trithiocyanuric acid, increased the sensitivity of detection in comparison with pure GCE. All processes were finally implemented in a microfluidic chip formed with a 3D printer by fused deposition modelling technology. As a material for chip fabrication, acrylonitrile butadiene styrene was chosen because of its mechanical and chemical stability. The chip contained the one chamber for the hydrolysis of the nucleic acid and
\end{abstract}


another for the electrochemical detection by the modified GCE. This chamber was fabricated to allow for replacement of the GCE.

Keywords: biosensor; lab-on-chip; electrochemistry; graphene; modification; hydrolysis; trithiocyanuric acid

\section{Introduction}

The microfluidic systems called lab-on-chip devices enables one to create fast and low cost detection systems with ultralow sample consumption [1]. Due to the fact that the electrochemical detection is still very attractive for its high sensitivity and inherent simplicity [2-4], some of these are often used to construct the mentioned microfluidic systems, including those aimed at detection of viruses [5] or DNA/RNA nucleobases [6,7]. However, the sensitivity of such microfluidic devices is still an issue. In this field, the utilization of various electrode surfaces such as carbon-based modifications and boron-doped diamond electrodes have enhanced the sensitivity and reproducibility [8]. For electrochemical detection of nucleobases by a glassy carbon electrode (GCE), the modification of graphene-based compounds altered by Nafion [9] or Nafion with $\mathrm{TiO}_{2}$ [10] has been also used to increase the sensitivity.

Graphene oxide (GO) is a multilayer system created by the oxidation of graphite and therefore oxygenated functionalities are introduced in the graphite structure [11]. This fact causes hydrophilicity and GO becomes very well soluble in water or other solvents utilized for numerous purposes [12-14]. GO has been widely applied for modification [15,16] of glassy carbon electrodes [17] used for the detection of metal ions, proteins, DNA mutations and other compounds [18].

Trithiocyanuric acid (ttc), also referred to as trimercaptotriazine, has a symmetric structure with three nitrogen atoms in a ring and three sulphur atoms connected to carbons, whereby these six atoms are highly reactive and can form bridges connecting central atoms. To illustrate the importance of trithiocyanuric acid, its use as a remediation agent for removal of heavy metals from industrial waters should be mentioned [19-21]. Removal of residual palladium from reaction mixtures in drug production is an especially important application of ttcNa3 [22-24]. This acid was also applied in plating processes, in production of composite materials with metals and rubbers and as an anticorrosion agent [25-28].

In this work, modified graphene oxide was used to develop a simple and sensitive method for detection of adenine in a hydrolysed miRNA sample. The modified graphene oxide was firstly dissolved in dimethylformamide and subsequently modified by Nafion and sonicated in an ultrasonic bath. The mixture was deposited on a glassy carbon surface. This way the layer for each measurement was prepared. The described modification allows adenine detection in the hydrolysed miRNA sample and it was possible to detect other nucleic bases too. Moreover, hydrolysis and electrochemical detection was carried out within a microfluidic chip with a chamber that allows repeatable input and output of the modified working electrode. 


\section{Experimental Section}

\subsection{Chemicals}

Ttc, thiodiacetic acid (tda), mercaptosuccinic acid (MSA), Nafion 117 (formulas are shown in Figure 1), titanium(IV) isopropoxide, graphite flakes, $\mathrm{NaNO}_{3}, \mathrm{KMnO}_{4}$, sodium acetate trihydrate, acetic acid, $\mathrm{Hg}\left(\mathrm{NO}_{3}\right)_{2}$, water and other chemicals were purchased from Sigma-Aldrich (St. Louis, MO, USA) in ACS purity (chemicals meet the specifications of the American Chemical Society). MiRNA was also purchased from Sigma-Aldrich and its sequence was 5' UAA GGC ACG CGG UGA AUG CCA AAA AAA AAA 3'. Standard nucleobases were adenine and cytosine (MP Biomedicals, Santa Ana, CA, USA), guanine and uracil (Sigma-Aldrich, St. Louis, MO, USA).

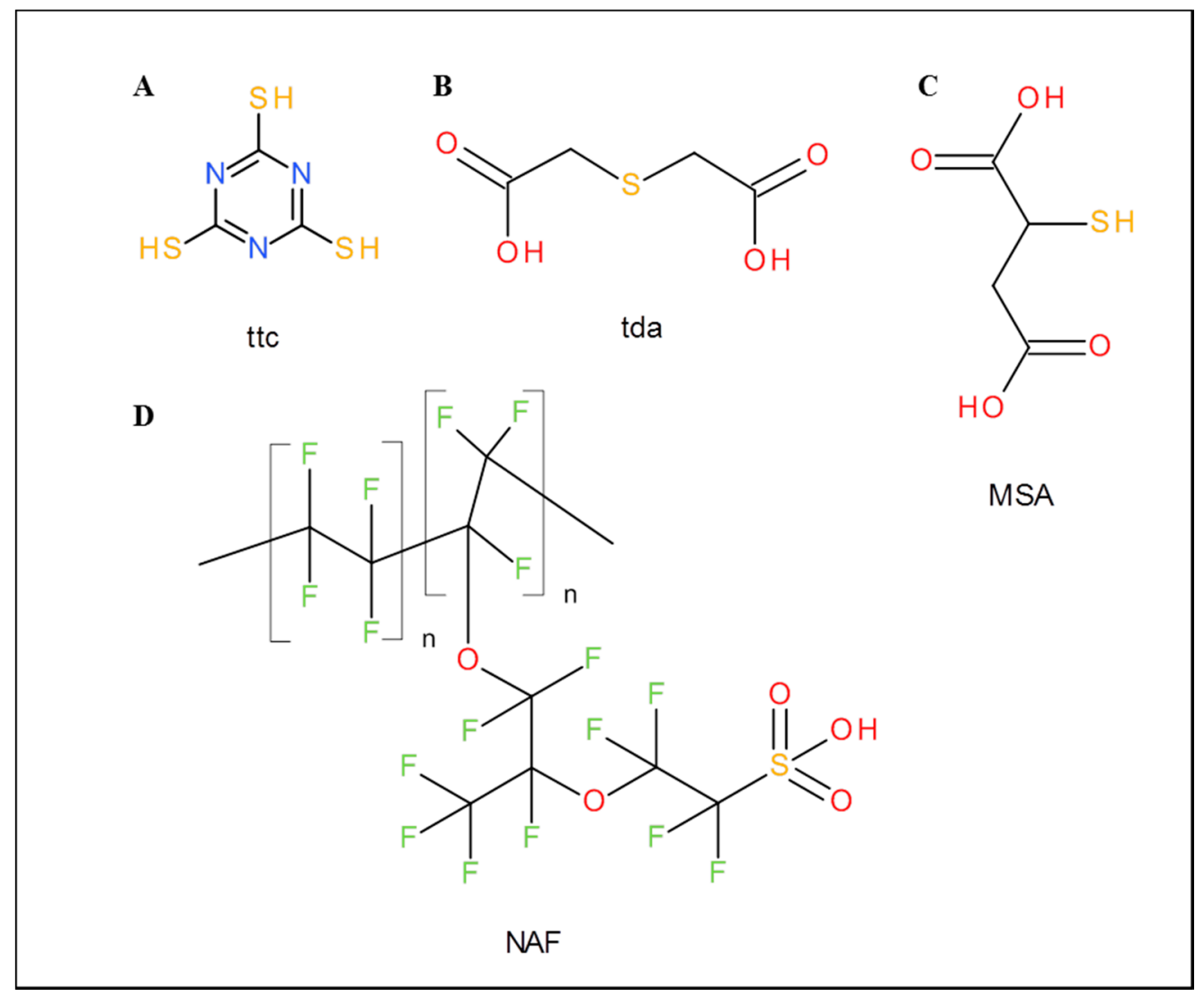

Figure 1. Schemes of compounds used for modification of graphene oxide. (A) ttc; (B) tda; (C) MSA; (D) Nafion (NAF).

\subsection{GO Modifications}

\subsubsection{Preparation of GO}

$\mathrm{GO}$ was prepared from graphite flakes by the Hummers method [29]. Briefly, graphite (2 $\mathrm{g}$ ), $\mathrm{NaNO}_{3}$ $(1 \mathrm{~g})$ and $\mathrm{KMnO}_{4}(6 \mathrm{~g})$ were added with stirring to concentrated $\mathrm{H}_{2} \mathrm{SO}_{4}(96 \%, w / w, 46 \mathrm{~mL})$ placed in an ice bath. The mixture was stirred overnight with gradual temperature growth. Water $(400 \mathrm{~mL})$ was slowly added and the mixture was heated at $90{ }^{\circ} \mathrm{C}$ for $2 \mathrm{~h}$. Subsequently, $\mathrm{H}_{2} \mathrm{O}_{2}(3 \%, v / v)$ was slowly 
added till colour turned to yellow. The product was decanted and washed several times with water. The final volume of the GO suspension was $200 \mathrm{~mL}$.

\subsubsection{Preparation of Modified GO (GO-ttc, GO-tda, and GO-MSA)}

In general, the samples were prepared as described in the previous paragraph by the following method: GO suspension $(25 \mathrm{~mL})$ in a $100 \mathrm{~mL}$ beaker was mixed with thiol compound (ttc, tda, or MSA in the amount of $0.5 \mathrm{~g}$ ) dissolved in water $(5 \mathrm{~mL})$. Samples were diluted with water and solution was shaken on orbital shaker overnight. The next step was decantation and washing several times with water. Samples were collected by centrifugation and dried at $60{ }^{\circ} \mathrm{C}$.

\subsubsection{Preparation of $\mathrm{GO}-\mathrm{TiO}_{2}$ Solution}

GO-ttc $(1 \mathrm{mg})$ in water: ethanol $(1: 1)$ mixture $(0.5 \mathrm{~mL})$ was sonicated $(1 \mathrm{~h})$. Titanium (IV) isopropoxide $(40 \mu \mathrm{L})$ was added and sonicated for $2 \mathrm{~h}$. The sample was centrifuged and solvent was discarded. Dimethylformamide was added $(0.85 \mathrm{~mL})$ and sonicated for $1 \mathrm{~h}$. Finally, Nafion $117(100 \mu \mathrm{L})$ was added and sample was sonicated for $0.5 \mathrm{~h}$. This solution was used for glassy carbon modification.

\subsubsection{Preparation of GO-thiol-Nafion Solutions (GO-ttc-NAF, GO-tda-NAF, and GO-MSA-NAF)}

These solutions were prepared as follows. $1 \mathrm{mg}$ of GO-thiol was suspended and sonicated in dimethylformamide $(1 \mathrm{~mL})$ for $2 \mathrm{~h}$. Then, Nafion $117(100 \mu \mathrm{L})$ was added and sonicated for $0.5 \mathrm{~h}$. This solution was used for glassy carbon modification.

\subsection{X-ray Fluorescence Analysis $(X R F)$}

The samples were analysed on Spectro Xepos (Spectro Analytical Instruments, Kleve, Germany) using anode X-ray tube with Pd anode working at a voltage of $44.69 \mathrm{kV}$ and a current of $0.55 \mathrm{~mA}$. Signals were detected with Barkla scatter aluminium oxide for $300 \mathrm{~s}$. For excitation three secondary targets (Mo, $\mathrm{Al}_{2} \mathrm{O}_{3}$ and high-ordered pyrolithic graphite crystal) were used. The excitation geometry was $90^{\circ}$. The samples were measured through the polyethylene bottle side wall $20 \mathrm{~mm}$ above the bottom. The Spectro Xepos software and TurboQuant method were applied for data analysis.

\subsection{Elemental Detection}

C, H, N and S detection of samples was carried out on Flash 2000 (Thermo Scientific, Waltham, MA, USA).

\subsection{Fourier Transformation Infrared Spectroscopy (FTIR)}

FTIR study was performed over the range of wavenumber $4000-400 \mathrm{~cm}^{-1}$ by a Bruker Vertex 70 FTIR spectrometer (Bruker, Ettlingen, Germany) using KBr pellets. 


\subsection{Sample Preparation for Electrochemical Detection of Nucleic Bases}

$24 \mu \mathrm{L}$ of $\mathrm{HCl}(\mathrm{pH}=2.9)$ was added to $24 \mu \mathrm{L}$ of $22 \mu \mathrm{M}$ miRNA and mixture was incubated at $99{ }^{\circ} \mathrm{C}$ for $1 \mathrm{~h}$ in Thermomixer comfort (Eppendorf Czech \& Slovakia s.r.o., Ricany, Czech Republic). After hydrolysis the mixture was neutralized by equimolar quantity of $\mathrm{NaOH}$. Hydrolysed samples were analysed electrochemically.

\subsection{Electrochemical Detection}

Electrochemical detection was carried out using a $\mathrm{CH}$ Instruments Electrochemical Workstation (CH Instruments, Bee Cave, TX, USA) and glass cell with three electrodes. $\mathrm{Ag} / \mathrm{AgCl} / 3 \mathrm{M} \mathrm{KCl}$ was used as a reference electrode and platinum as a counter electrode. As a working electrode, modified GCE was used. This GCE was modified by various types of chemically modified graphene oxide (Table 1, Figure 1). Five $\mu \mathrm{L}$ of chemically modified graphene oxide in dimethylformamide was applied on the GCE and dried with a hair drier for $15 \mathrm{~min}$. For all measurement differential pulse voltammetry was used and measurement parameters were as follows: initial potential $0.2 \mathrm{~V}$, final potential $1.5 \mathrm{~V}$ for adenine and $1.8 \mathrm{~V}$ for simultaneous detection of bases and hydrolysed sample, step potential 0.004 , modulation amplitude $0.05 \mathrm{~V}$, pulse width $0.2 \mathrm{~s}$, sampling width $0.0167 \mathrm{~s}$, pulse period $0.5 \mathrm{~s}$, quiet time $10 \mathrm{~s}$. All experiments were performed at room temperature. As the supporting electrolyte the acetate buffer $\left(\mathrm{pH}=5,0.2 \mathrm{M} \mathrm{CH}_{3} \mathrm{COOH}\right.$ and $0.2 \mathrm{M} \mathrm{CH}_{3} \mathrm{COONa}$ ) was used. $1 \mathrm{ml}$ of electrolyte was used for adenine detection and $0.5 \mathrm{~mL}$ for simultaneous detection of bases and hydrolysed sample. The limit of detection was calculated by LOD $=\frac{3.3 \times S D}{S}, S D=$ standard deviation of the response and $S=$ slope of the calibration curve.

Table 1. Chemical agents used for modification of graphene oxide.

\begin{tabular}{cc}
\hline Abbreviation & Applied Modifiers \\
\hline GO-MSA-NAF & mercaptosuccinic acid and Nafion \\
GO-tda-NAF & thiodiacetic acid and Nafion \\
GO-ttc & trithiocyanuric acid \\
GO-ttc-NAF & trithiocyanuric acid and Nafion \\
GO-TiO $_{2}$ & trithiocyanuric acid, Nafion and titanium dioxide \\
\hline
\end{tabular}

\subsection{Microfluidic Detection System}

Electrodes were placed to a holder fabricated by using a 3D printer (Profi3Dmaker, 3D Factories, Straznice, Czech Republic) using Fused Deposition Modelling (FDM) technology. For electrochemical detection in the microfluidic system different electrodes were chosen due to their size. Standard $\mathrm{Ag} / \mathrm{AgCl} / 3 \mathrm{M} \mathrm{KCl}$ was replaced with quasi-reference electrode as graphite lead and as a counter electrode a platinum electrode with diameter $0.5 \mathrm{~mm}$ (CH Instruments, Bee Cave, TX, USA) was used. 


\section{Results and Discussion}

\subsection{Characterisation of Graphene Modified Materials}

\subsubsection{X-Ray Fluorescence Spectroscopy and Elemental Analysis}

Modified GO was prepared by mixing of a water suspension of GO with sulphur-containing compounds. It was easily seen that the samples changed in colour from light brown to deep brown or black during overnight mixing. Prepared samples were decanted and washed several times with water to remove excess reagents. Solid samples were obtained by centrifugation and drying. Composition of the modified GO was proved by X-ray fluorescence spectroscopy and elemental analysis. The presence of sulphur in all the samples was proved by peak characteristic for $\mathrm{S}_{\mathrm{K} \alpha}$, which appeared in all XRF spectra. The peak position was always the same, whereas the intensity of the peak was changing. That is why only one typical spectrum is shown in Figure 2A (top) for GO-ttc. XRF spectrum of GO-TiO2, where peak TiKa was also observed (Figure 2A (bottom)) and thus presence of $\mathrm{Ti}$ in the sample was unambiguously proved, was the only exception. $\mathrm{C}, \mathrm{H}, \mathrm{N}$, and $\mathrm{S}$ elemental analysis of samples also proved the presence of sulphur and content of carbon and nitrogen in the case of trithiocyanuric acid (Table 2).

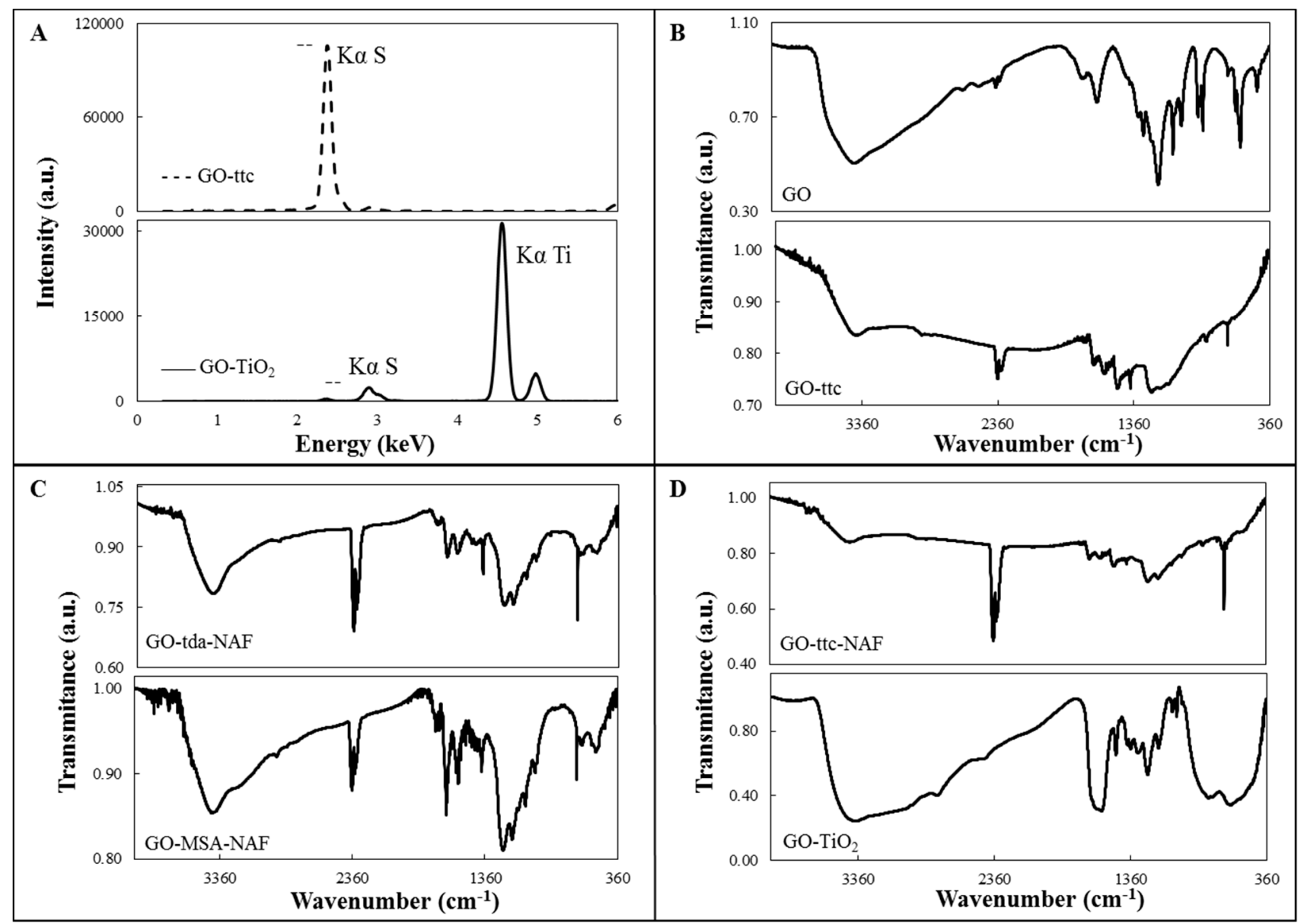

Figure 2. Characterization of graphene oxide modified materials. (A) XRF analysis of GO-ttc (dashed line) and GO-TiO 2 (solid line); (B-D) IR spectra of studied materials. 
Table 2. Elemental analysis results of various modified graphene oxides.

\begin{tabular}{ccccc}
\hline & Nitrogen (\%) & Carbon (\%) & Hydrogen (\%) & Sulphur (\%) \\
\hline GO & 0 & 84.15 & 0.44 & 0 \\
GO-MSA & 0 & 43.27 & 2.34 & 15.45 \\
GO-tda & 0 & 38.06 & 2.89 & 20.77 \\
GO-ttc & 10.14 & 52.95 & 1.35 & 25.95 \\
$\mathrm{GO}^{-T i O}{ }_{2}$ & 6.56 & 34.12 & 0.78 & 16.02 \\
\hline
\end{tabular}

\subsubsection{FTIR Analysis}

FTIR spectra of GO and modified GO are shown in Figures 2B-D. The presence of oxygen containing groups such as carbonyl, carboxylic acid, epoxy and hydroxyl in the GO is proved by the presence of the corresponding characteristic peaks. These peaks can be attributed to $v(\mathrm{C}=\mathrm{O})$ stretching $\left(1663 \mathrm{~cm}^{-1}\right)$, C-O-C stretching $\left(1193 \mathrm{~cm}^{-1}\right), v(\mathrm{C}-\mathrm{O})$ stretching $\left(1072 \mathrm{~cm}^{-1}\right)$ and a broad shoulder with a maximum at $3480 \mathrm{~cm}^{-1}$ can be assigned to vibration of hydroxyl groups [30]. The spectrum of GO modified with Nafion (GO-NAF) (not shown) was also measured. In the GO-NAF spectrum there is very broad band from $400-800 \mathrm{~cm}^{-1}$, probably due to $\mathrm{CO}$ vibrations, and very weak peaks in the $1212-1232 \mathrm{~cm}^{-1}, 1150-1160 \mathrm{~cm}^{-1}$ and $1056-1105 \mathrm{~cm}^{-1}$ regions that can be assigned to $v_{\text {as }}\left(\mathrm{CF}_{2}\right)$, $v_{\mathrm{s}}\left(\mathrm{CF}_{2}\right)$ and $v_{\mathrm{s}}(\mathrm{SO})$, respectively [31]. The same peaks, of weak or medium intensity, were found in the spectra of Nafion-containing samples. In the spectra of all compounds, except for the GO spectrum, there is very strong peak near $670 \mathrm{~cm}^{-1}$ characteristic for sulphur-containing compounds, attributable to $v(\mathrm{C}-\mathrm{S})$. In the spectra of GO-tda-NAF and GO-MSA-NAF (Figure 2C) there are, in comparison with the GO spectrum, more intense peaks near 1560 and $1388 \mathrm{~cm}^{-1}$, which can be attributed to $v_{\text {as }}(\mathrm{COO})$ and $v_{\mathrm{s}}(\mathrm{COO})$ vibrations, respectively [32]. In the spectra of ttc-modified GO, peaks in the 1248-1265 and 1529-1589 $\mathrm{cm}^{-1}$ regions were found, which can be attributed to $v(\mathrm{C}-\mathrm{N})$ vibrations of the heterocyclic ring and peaks near $870 \mathrm{~cm}^{-1}$ which are most probably connected with $v(\mathrm{C}-\mathrm{S})$ vibrations [33]. In the spectrum of $\mathrm{GO}-\mathrm{TiO}_{2}$ a shoulder from 400 to $670 \mathrm{~cm}^{-1}$ was observed, which is probably caused by the presence of the Ti-O stretching vibration. Thus, the modification of GO by $\mathrm{TiO}_{2}$ on the surface was confirmed.

\subsection{Electrochemical Detection of Nucleobases in Electrochemical Cell}

The first step of the detection part of the experiment involved testing of five variously modified graphene oxides for adenine detection. The electrochemical detection was performed by differential pulse voltammetry using a GCE modified with specific graphene oxides. Figure 3A depicts voltammograms of these modifications with the characteristic peak for adenine, which was detected at approximately $1.0 \mathrm{~V}$. The highest sensitivities were found for modifications with trithiocyanuric acid. According to $[9,10]$, we attempted to improve the sensitivity by Nafion and $\mathrm{TiO}_{2}$, respectively. In the case of modification by $\mathrm{TiO}_{2}$, the sensitivity decreased, but for GO-ttc-NAF higher sensitivity than without Nafion was found. Voltammograms of GO-ttc, GO-ttc-NAF and GO-TiO 2 show another peak at a potential of about $1.4 \mathrm{~V}$. This peak is probably connected with oxidation of the material itself. The high sensitivity of trithiocyanuric acid to nucleobases was probably caused by its ability to form hydrogen bonds with compounds containing nitrogen [34]. The addition of Nafion had a few 
supplemental positive results. It prevented graphene from aggregation and increased the stability of the immobilisation of graphene on GCE. The negative charge of Nafion can facilitate adsorption of positively charged nucleobases. Nafion also increased the oxidation signal due to the easier electron transfer [9]. Based on these advantages we assume this modification GO-ttc-NAF has great potential for wide electrochemical application. The next step was the determination of calibration curves for adenine on unmodified GCE and GCE modified by GO-ttc-NAF. Both curves fitted by linear regression are depicted in Figure 3B. Analytical parameters like regression parameters, standard deviation, limit of detection and quantification are listed in Tables 3 and 4. We observed quite similar limits of detection for unmodified and modified GCE. Although the sensitivity of applied electrochemical method using modified GCE was five times higher, the dissimilar surface of the modified electrode caused a high standard deviation which resulted in a detection limit decrease.

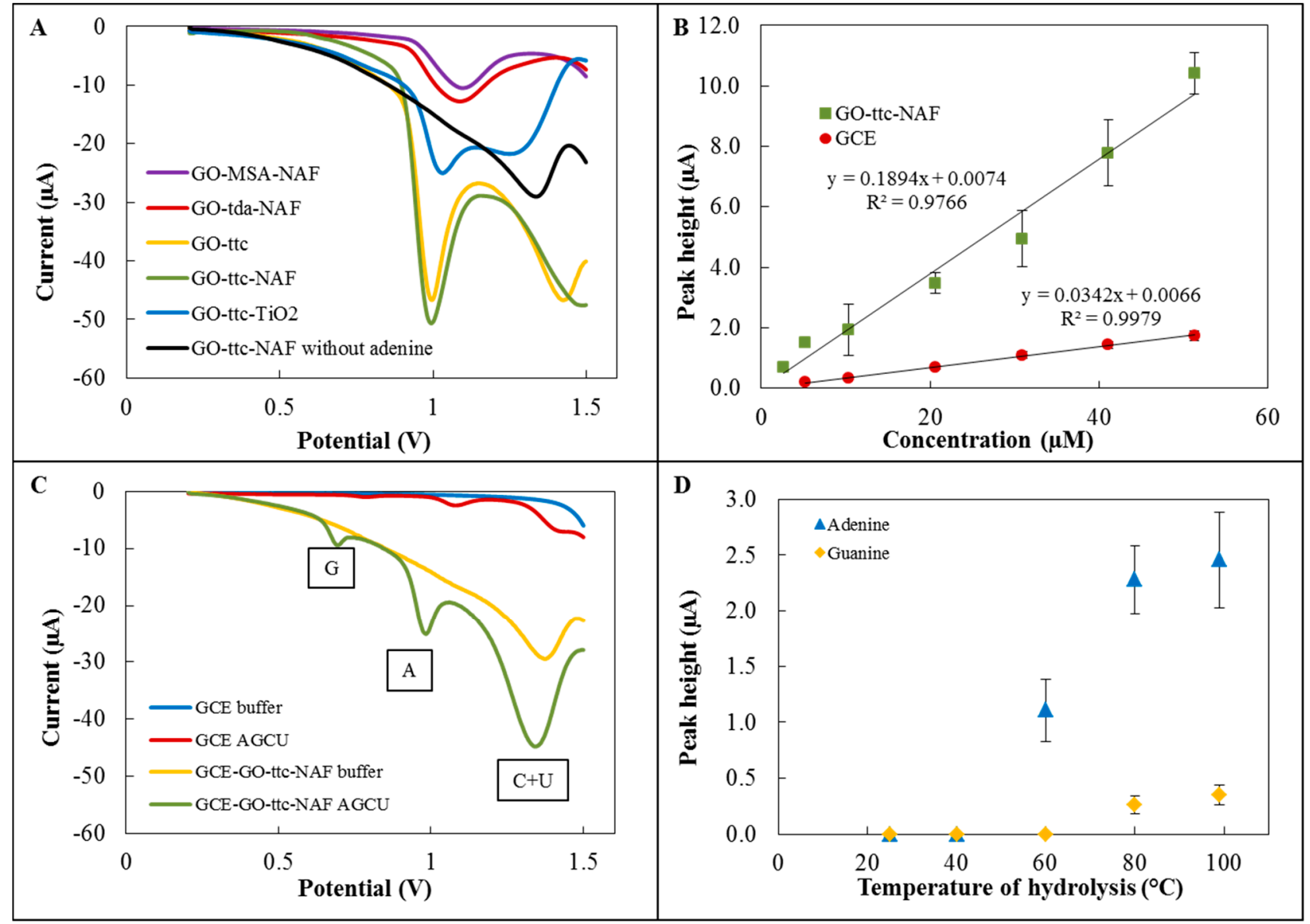

Figure 3. (A) Detection of $200 \mu \mathrm{M}$ adenine on GCE modified by different graphene oxide; (B) Calibration curve of adenine on unmodified GCE and GCE modified by GO-ttc-NAF; repeated in triplicates; $(\mathbf{C})$ Simultaneous detection of guanine $(262 \mu \mathrm{M})$, adenine $(51 \mu \mathrm{M})$ and cytosine $(273 \mu \mathrm{M})$ with uracil $(255 \mu \mathrm{M})$ by unmodified GCE and GCE modified by GO-ttc-NAF; (D) Optimization of hydrolysis temperature measured by GCE modified with GO-ttc-NAF, concentration of adenine and guanine was $9 \mu \mathrm{M}$ and $4 \mu \mathrm{M}$ respectively. 
Table 3. Analytical parameters of electrochemical detection of unmodified GCE, $n=3$.

\begin{tabular}{|c|c|c|c|c|c|c|c|c|c|}
\hline Substance & Regression Equation & $\begin{array}{c}\text { Linear Dynamic } \\
\text { Range }(\boldsymbol{\mu M}) \\
\end{array}$ & $\begin{array}{c}\text { Linear Dynamic } \\
\text { Range }(\mu \mathrm{g} / \mathrm{mL})\end{array}$ & $\mathbf{R}^{1,2}$ & $\begin{array}{l}\text { LOD }^{2} \\
(\mu \mathrm{M})\end{array}$ & $\begin{array}{c}\text { LOD } \\
(\mu \mathrm{g} / \mathrm{mL})\end{array}$ & $\begin{array}{r}\mathrm{LOQ}^{3} \\
(\mu \mathrm{M})\end{array}$ & $\begin{array}{c}\text { LOQ } \\
(\mu \mathrm{g} / \mathrm{mL}) \\
\end{array}$ & $\begin{array}{c}\text { RSD }^{4} \\
(\%) \\
\end{array}$ \\
\hline $\begin{array}{l}\text { unmodified } \\
\text { GCE }\end{array}$ & $y=0.0342 x-0.0066$ & $5.18-51.30$ & $0.70-6.93$ & 0.9979 & 0.67 & 0.09 & 2.23 & 0.30 & 3.72 \\
\hline
\end{tabular}

Table 4. Analytical parameters of electrochemical detection of GCE modified by CO-ttc-NAF, $n=3$.

\begin{tabular}{|c|c|c|c|c|c|c|c|c|c|}
\hline Substance & Regression Equation & $\begin{array}{c}\text { Linear Dynamic } \\
\text { Range }(\mu \mathrm{M}) \\
\end{array}$ & $\begin{array}{l}\text { Linear Dynamic } \\
\text { Range }(\mu \mathrm{g} / \mathrm{mL})\end{array}$ & $\mathbf{R}^{1,2}$ & $\begin{array}{l}\text { LOD }^{2} \\
(\mu \mathrm{M})\end{array}$ & $\begin{array}{c}\text { LOD } \\
(\mu \mathrm{g} / \mathrm{mL}) \\
\end{array}$ & $\begin{array}{c}\mathbf{L O Q}^{3} \\
(\mu \mathrm{M})\end{array}$ & $\begin{array}{c}\text { LOQ } \\
(\mu \mathrm{g} / \mathrm{mL}) \\
\end{array}$ & $\begin{array}{r}\text { RSD }^{4} \\
(\%)\end{array}$ \\
\hline $\begin{array}{c}\text { modified } \\
\text { GCE }\end{array}$ & $y=0.1894 x-0.0074$ & $2.59-51.30$ & $0.35-6.93$ & 0.9766 & 0.66 & 0.09 & 2.21 & 0.30 & 5.95 \\
\hline
\end{tabular}

Furthermore, simultaneous detection of all nucleobases was performed on GCE modified by GO-ttc-NAF. Figure 3C shows a comparison between detection on this modified GCE and unmodified GCE. By using of GCE modified by GO-ttc-NAF three peaks may be observed. The peaks at potentials of $0.75 \mathrm{~V}$ and $1.0 \mathrm{~V}$ belong to guanine and adenine, respectively. The last peak at a potential of about $1.4 \mathrm{~V}$ was a signal of cytosine and uracil, which had peaks at the same potential and thus it is not possible to distinguish between them. The one disadvantage of GCE modified by GO-ttc-NAF was the peak of the material itself, which occurred at the same potential as the peak for cytosine and uracil. For this reason it was not possible to determine small amounts of cytosine and uracil. It should be noted that the best sensitivity was determined for adenine which shows a very high peak at a concentration of $51 \mu \mathrm{M}$ in contrast to other nucleobases, whose concentrations were about $260 \mu \mathrm{M}$.

\subsection{Optimization of the Hydrolysis Process}

The optimization was carried out for adenine and guanine detection at different temperatures of hydrolysis as follows: $25^{\circ} \mathrm{C}, 40^{\circ} \mathrm{C}, 60^{\circ} \mathrm{C}, 80^{\circ} \mathrm{C}$ and $99^{\circ} \mathrm{C}$ (Figure 3D). At $25^{\circ} \mathrm{C}$ and $40{ }^{\circ} \mathrm{C}$ no signal was observed for either adenine or guanine. At $60{ }^{\circ} \mathrm{C}$ the adenine peak occurred, but the peak for guanine was not observed. Both peaks were found for temperatures of hydrolysis of $80{ }^{\circ} \mathrm{C}$ and $99{ }^{\circ} \mathrm{C}$. The difference between the signals was insignificant (about $0.1 \mu \mathrm{A}$ ).

\subsection{Microfluidic System}

Connection of the hydrolysis process and electrochemical detection of nucleobases was the great challenge and therefore microfluidic system was designed and fabricated. The microfluidic system was composed of two basic parts: the first part was for hydrolysis, the second one for the electrochemical detection. The principle scheme of the suggested system is shown in Figure 4A. The fluidic system was realized by plastic tubes. The liquid movements were done using three syringe pumps, three three-step valves and three magnetic valves. The microfluidic chip was printed by a 3D printer and as 
a material for printing, acrylonitrile butadiene styrene was chosen because of its thermal and chemical stability.

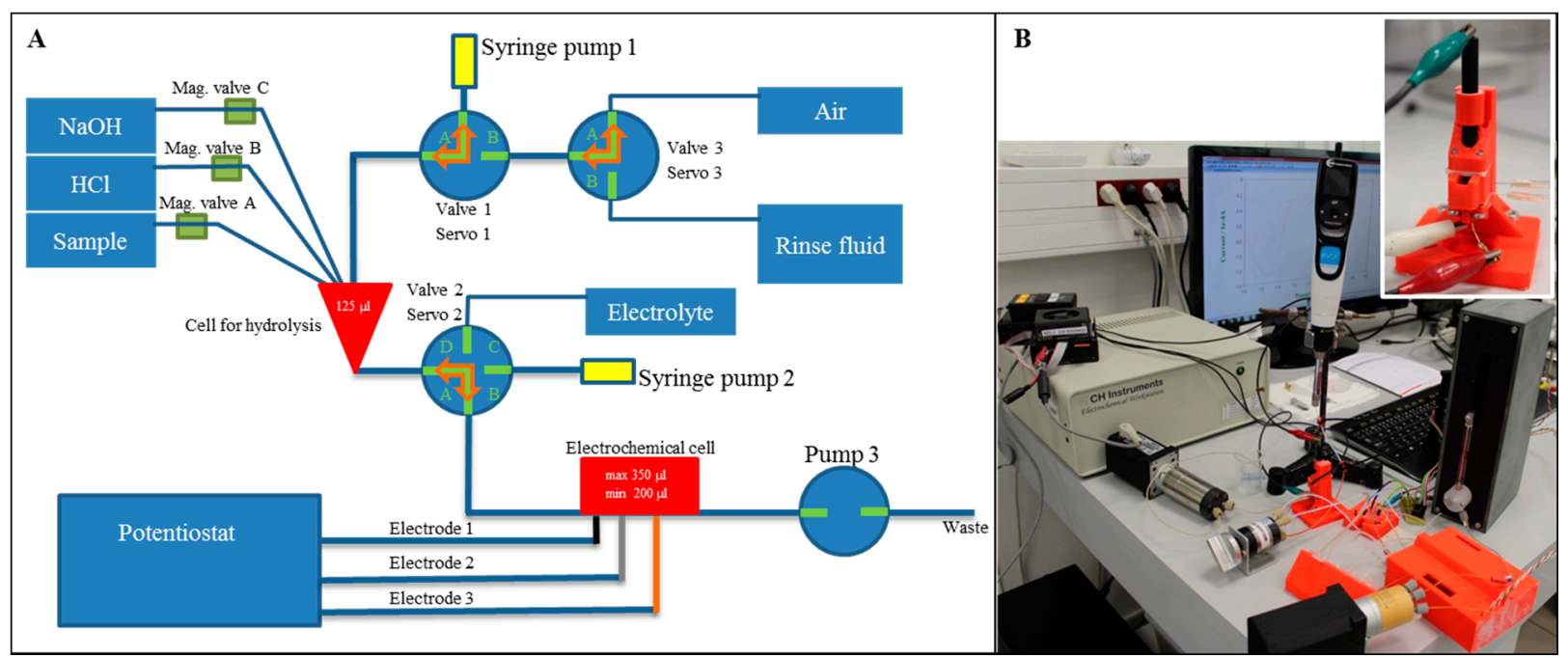

Figure 4. (A) The scheme of the microfluidic system composed of the hydrolysis and detection parts; (B) Picture of the fabricated microfluidic system and detailed picture of the chip with integrated electrodes.

\subsubsection{Hydrolysis Part}

The first part of the system designed for the hydrolysis process contained three inputs and one output to the second part of the system. The chamber comprised three basic parts as follows: model cover, body and heaters case. The hydrolysis chamber had a volume of $125 \mu \mathrm{L}$ and it was cone-shaped to ensure the greatest possible outflow. In the body, there were PT100 temperature sensors (which resistance is linearly dependent on temperature changes). These three sensors were placed at different radius from the centre, where the sample was placed. The body had a cylindrical shape with a height of $8 \mathrm{~mm}$ and $30 \mathrm{~mm}$ in diameter. In the body there were three screw holes with M4 thread.

The cover had a drum shape with $30 \mathrm{~mm}$ in diameter and $6 \mathrm{~mm}$ in height. There were holes for input to the hydrolysis chamber. It also contained a recess for three M4 Allen screws, which connected the cover and the body tightly together to protect samples from evaporation. The major advantage was printing of seals from flexible material which prevented the evaporation.

The heater case had a square shape with side length of $50 \mathrm{~mm}$ and height of $15 \mathrm{~mm}$. In the centre of heater case there was a space for the body and the cover. This space was in the form of rolls with 31 $\mathrm{mm}$ in diameter and it is $14 \mathrm{~mm}$ high. Due to the larger size, it was possible to glue an adhesive CU tape on the body to spread a heat uniformly to the centre of body. The cabling for four heaters led from the centre of the heater case. Heaters were at the same distance from the centre axis and from each other. They were placed $20 \mathrm{~mm}$ from the centre and at the same height as the centre cell in the body. Cabling was led to one side of the heaters case and then on the other side, next was led out from the body. The part of the system designed to hydrolyse the sample was controlled by a unit which regulated the temperature in the chip at the required temperature $\left(100{ }^{\circ} \mathrm{C}\right)$ by $2{ }^{\circ} \mathrm{C}$ hysteresis. The control unit regulated the temperature on the outer part of chamber (12 $\mathrm{mm}$ from the centre), in the 
central part of body ( $8 \mathrm{~mm}$ from the centre) and also directly near to the hydrolysis chamber. Hence it was possible easily regulate the thermal transmittance and short-term overheating did not exceeded over than $1.5^{\circ} \mathrm{C}$. Heaters were turned on by a $12 \mathrm{~V}$ bipolar transistor.

\subsubsection{Detection Part}

The second part of the chip was designed for electrochemical detection. There were two inputs and one output. The main parts of the detection unit were made by a $3 \mathrm{D}$ printer from acrylonitrile butadiene styrene material as follows: holder, detection cell an pressure cover. The whole construct was completed by two sealing parts. The seals were also made by the 3D printer but from a flexible material (Elastic Printplus Natural from 3DFactories). The seals had a square shape and the height was $0.9 \mathrm{~mm}$. The holes for electrode were in the centres of individual seals and these holes had a circular shape with 6 or $3 \mathrm{~mm}$ in diameter.

The model holder had a wedge shape and it had to hold the detection cell in the angle $10^{\circ}$ from the horizontal pad on which it stood. It also contained holes for M3 screws which pressed all the parts tightly together. In the holder, there was the hole for the working electrode (modified glassy carbon) with $6.3 \mathrm{~mm}$ in diameter. This hole had larger diameter $(6.5 \mathrm{~mm})$ for easier replacement of electrode.

The model detection cell had rectangular ground plan with sides of dimension $15 \times 20 \mathrm{~mm}$ and $7 \mathrm{~mm}$ height. It contained four holes for mounting M3 screws and a detection chamber with a volume of $430 \mu \mathrm{L}$. The cell surface was smoothed by a borer with $6 \mathrm{~mm}$ in diameter. The pressure cover had a square shape with size $15 \mathrm{~mm}$, the height was $5 \mathrm{~mm}$ and there were holes for holding by M3 screws. Holes with $0.5 \mathrm{~mm}$ in diameter were drilled for electrodes.

The whole chip part for detection was assembled using four screws M3 and nuts. Thanks to these screws the tightness of the whole chip was ensured. The working electrode was led from below the chip and it was placed in a position where the electrode was always immersed in electrolyte (minimal volume $200 \mu \mathrm{L}$ ). Other two electrodes were placed opposite the main electrode and their position was near the bottom of the detection cell, so these electrodes were also always completely immersed in the electrolyte. The electrodes did not touch each other. Two inputs in the form of insulin needles led to the detection cell. One from this input served as an output (the input closer to the working electrode, because there was the lowest point of whole model). All electrodes were connected to the Electrochemical Workstation (Ch Instruments, Bee Cave, TX, USA). The basic system operation is described in detail in the Supplementary Material.

\subsection{Analysis of Sample in Microfluidic System}

The hydrolysis of miRNA and subsequent electrochemical detection were performed using the 3D fabricated microfluidic system (Figure 4B). The hydrolysis was carried out in hydrolysis cell by $\mathrm{HCl}$ $(\mathrm{pH}=2.9)$ at $99^{\circ} \mathrm{C}$ for 1 hour. Then the sample was neutralized by an equimolar amount of $\mathrm{NaOH}$ and the whole volume was transported to the electrochemical detection cell. A graphite electrode was used as a reference electrode, platinum as a counter electrode and GCE modified by GO-ttc-NAF as a working electrode. The oxidation peak of adenine occurred at $0.85 \mathrm{~V}$ (Figure 5A) and the peak of guanine (Figure 5B) occurred at $0.54 \mathrm{~V}$; all measurements were done three times. The reason why we were also interested in guanine oxidation peak evaluation was the transformation of adenine to guanine 
nucleobases during the hydrolysis process. For the lowest concentration of miRNA the peak for adenine was detected, but this was not the case of guanine. Therefore the presented calibration curve for guanine (Figure 5B) contains the point for zero peak height. Both peaks were evaluated according to various concentrations of hydrolysed miRNA. The concentrations of adenine and guanine presented in Figure 5A and 5B were recalculated according to the amount of each nucleobase in miRNA (15 times adenine, seven times guanine). Both peaks increased with increasing concentration of hydrolysed miRNA which proved the functionality of the proposed microfluidic detection system. The obtained sensitivity of detection (Figure 5A) in the microfluidic system was lower in comparison to the determination in an electrochemical cell (Figure 3B) due to the smaller auxiliary electrode surface.

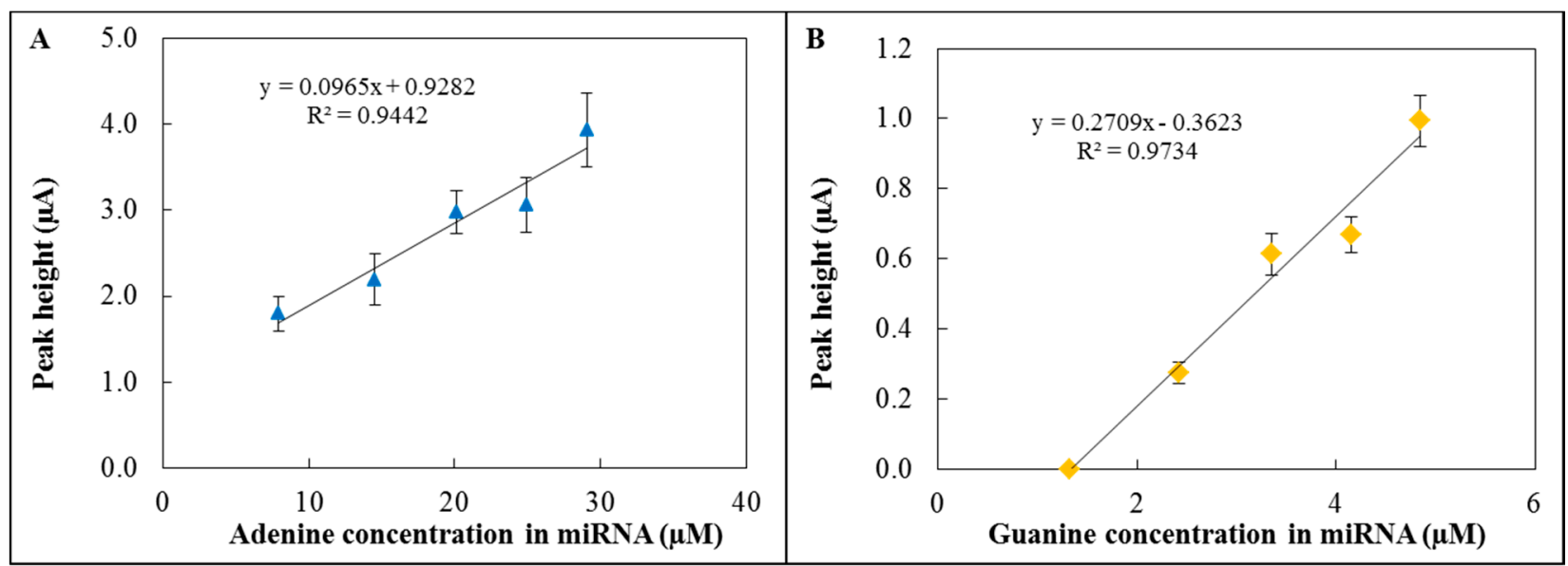

Figure 5. Calibration curves related to the electrochemical detection of (A) adenine and (B) guanine in hydrolysed miRNA in the microfluidic system; repeated in triplicate. Presented amounts of adenine and guanine are based on miRNA sequence recalculation.

\section{Conclusions}

Due to the growing interest in miRNA and its detection, the focus on technologies which allow the detection of these compounds is understandable. The electrochemical determination technique is among the more infrequently used methods. In this article a new lab-on-chip device for electrochemical determination of nucleic bases in hydrolysed miRNA is presented. For detection, a modified graphene oxide electrode was used as working electrode resulting in an increased detection sensitivity compared to an unmodified graphene oxide electrode. This model provides user friendly possibility of nucleic acids bases detection, including steps that are done automatically in one system.

\section{Acknowledgments}

Financial support from the project NanoBioTECell P102/11/1068 is highly acknowledged.

\section{Author Contributions}

Jana Vlachova: performed electrochemical measurements, wrote manuscript; Katerina Tmejova: performed electrochemical measurements, wrote manuscript; Pavel Kopel: made a suggestion and prepared GO modifications; Maria Korabik: FTIR analysis; Jan Zitka: wrote manuscript, preparation 
of microfluidic chip; David Hynek: wrote manuscript, summarization of results; Jindrich Kynicky: X-ray fluorescence analysis; Vojtech Adam: design of experiment, wrote manuscript; Rene Kizek: wrote manuscript, led experiment.

\section{Conflicts of Interest}

The authors declare no conflict of interest.

\section{References}

1. Figeys, D.; Pinto, D. Lab-on-a-chip: A revolution in biological and medical sciences. Anal. Chem. 2000, 72, 330A-335A.

2. Nejdl, L.; Kudr, J.; Cihalova, K.; Chudobova, D.; Zurek, M.; Zalud, L.; Kopecny, L.; Burian, F.; Ruttkay-Nedecky, B.; Krizkova, S.; et al. Remote-controlled robotic platform ORPHEUS as a new tool for detection of bacteria in the environment. Electrophoresis 2014, 35, 2333-2345.

3. Prasek, J.; Adamek, M.; Hubalek, J.; Adam, V.; Trnkova, L.; Kizek, R. New hydrodynamic electrochemical arrangement for cadmium ions detection using thick-film chemical sensor electrodes. Sensors 2006, 6, 1498-1512.

4. Bonanni, A.; Loo, A.H.; Pumera, M. Graphene for impedimetric biosensing. TrAC Trends Anal. Chem. 2012, 37, 12-21.

5. Krejcova, L.; Nejdl, L.; Rodrigo, M.A.M.; Zurek, M.; Matousek, M.; Hynek, D.; Zitka, O.; Kopel, P.; Adam, V.; Kizek, R. 3D printed chip for electrochemical detection of influenza virus labeled with CdS quantum dots. Biosens. Bioelectron. 2014, 54, 421-427.

6. Huang, K.J.; Niu, D.J.; Sun, J.Y.; Han, C.H.; Wu, Z.W.; Li, Y.L.; Xiong, X.Q. Novel electrochemical sensor based on functionalized graphene for simultaneous determination of adenine and guanine in DNA. Colloid Surf. B-Biointerfaces 2011, 82, 543-549.

7. Dubuisson, E.; Yang, Z.Y.; Loh, K.P. Optimizing Label-Free DNA Electrical Detection on Graphene Platform. Anal. Chem. 2011, 83, 2452-2460.

8. Pumera, M., Nanomaterials meet microfluidics. Chem. Commun. 2011, 47, 5671-5680.

9. Yin, H.S.; Zhou, Y.L.; Ma, Q.A.; Ai, S.Y.; Ju, P.; Zhu, L.S.; Lu, L.N. Electrochemical oxidation behavior of guanine and adenine on graphene-Nafion composite film modified glassy carbon electrode and the simultaneous determination. Process. Biochem. 2010, 45, 1707-1712.

10. Fan, Y.; Liu, J.H.; Lu, H.T.; Zhang, Q. Electrochemical behavior and voltammetric determination of paracetamol on Nafion/TiO2-graphene modified glassy carbon electrode. Colloid Surf. B-Biointerfaces 2011, 85, 289-292.

11. Dreyer, D.R.; Park, S.; Bielawski, C.W.; Ruoff, R.S. The chemistry of graphene oxide. Chem. Soc. Rev. 2010, 39, 228-240.

12. Xing, X.B.; Zheng, J.P.; Sun, C.; Li, F.J.; Zhu, D.B.; Lei, L.; Cai, X.; Wu, T. Graphene oxide-deposited microfiber: A new photothermal device for various microbubble generation. Opt. Express 2013, 21, 31862-31871. 
13. Yu, S.J.; Jiang, Y.M.; Wang, C.M. A polymer composite consists of electrochemical reduced graphene oxide/polyimide/chemical reduced graphene oxide for effective preparation of SnSe by electrochemical atomic layer deposition method with enhanced electrochemical performance and surface area. Electrochim. Acta 2013, 114, 430-438.

14. Borini, S.; White, R.; Wei, D.; Astley, M.; Haque, S.; Spigone, E.; Harris, N.; Kivioja, J.; Ryhanen, T. Ultrafast Graphene Oxide Humidity Sensors. ACS Nano 2013, 7, 11166-11173.

15. Sanghavi, B.; Wolfbeis, O.; Hirsch, T.; Swami, N. Nanomaterial-based electrochemical sensing of neurological drugs and neurotransmitters. Microchim. Acta 2014, 182, 1-41.

16. Sanghavi, B.J.; Sitaula, S.; Griep, M.H.; Karna, S.P.; Ali, M.F.; Swami, N.S. Real-Time Electrochemical Monitoring of Adenosine Triphosphate in the Picomolar to Micromolar Range Using Graphene-Modified Electrodes. Anal. Chem. 2013, 85, 8158-8165.

17. Shi, Q.F.; Chen, M.; Diao, G.W. Electrocatalytical reduction of m-nitrophenol on reduced graphene oxide modified glassy carbon electrode. Electrochim. Acta 2013, 114, 693-699.

18. Wang, L.; Lu, X.P.; Ye, Y.J.; Sun, L.L.; Song, Y.H. Nickel-cobalt nanostructures coated reduced graphene oxide nanocomposite electrode for nonenzymatic glucose biosensing. Electrochim. Acta 2013, 114, 484-493.

19. Henke, K.R.; Robertson, D.; Krepps, M.K.; Atwood, D.A. Chemistry and stability of precipitates from aqueous solutions of 2,4,6-trimercaptotriazine, trisodium salt, nonahydrate (TMT-55) and mercury (II) chloride. Water Res. 2000, 34, 3005-3013.

20. Henke, K.R.; Hutchison, A.R.; Krepps, M.K.; Parkin, S.; Atwood, D.A. Chemistry of 2,4,6-trimercapto-1,3,5-triazine (TMT): Acid dissociation constants and group 2 complexes. Inorg. Chem. 2001, 40, 4443-4447.

21. Bailey, J.R.; Hatfield, M.J.; Henke, K.R.; Krepps, M.K.; Morris, J.L.; Otieno, T.; Simonetti, K.D.; Wall, E.A.; Atwood, D.A. Transition metal complexes of 2,4,6-trimercapto-1,3,5-triazine (TMT): potential precursors to nanoparticulate metal sulfides. J. Organomet. Chem. 2001, 623, 185-190.

22. Rosso, V.W.; Lust, D.A.; Bernot, P.J.; Grosso, J.A.; Modi, S.P.; Rusowicz, A.; Sedergran, T.C.; Simpson, J.H.; Srivastava, S.K.; Humora, M.J.; et al. Removal of palladium from organic reaction mixtures by trimercaptotriazine. Org. Process. Res. Dev. 1997, 1, 311-314.

23. Ishihara, K.; Nakayama, M.; Kurihara, H.; Itoh, A.; Haraguchi, H. Removal of palladium(II) from aqueous and organic solutions by polystyrene-bound trimercaptotriazine. Chem. Lett. 2000, 1218-1219, doi:10.1246/cl.2000.1218.

24. Garrett, C.E.; Prasad, K. The art of meeting palladium specifications in active pharmaceutical ingredients produced by Pd-catalyzed reactions. Adv. Synth. Catal. 2004, 346, 889-900.

25. Hirahara, H.; Mori, K.; Oishi, Y. Direct adhesion of fluorinated rubbers to nickel-plated steel and nitrile rubber during curing using the tetrabutylammonium salt of 1,3,5-triazine-2,4,6-trithiol. J. Adhes. Sci. Technol. 1997, 11, 1459-1474.

26. Hirahara, H.; Aisawa, S.; Mori, K.; Narita, E.; Oishi, Y. Study of interfacial chemistry on direct curing adhesion between $\mathrm{Ni}-\mathrm{P}$ plating and rubber using 1,3,5-triazine-2,4,6-trithiol monosodium salt. Surf. Interface Anal. 2003, 35, 953-959.

27. Chen, W.; Hong, S.; Xiang, B.; Luo, H.Q.; Li, M.; Li, N.B. Corrosion inhibition of copper in hydrochloric acid by coverage with trithiocyanuric acid self-assembled monolayers. Corros. Eng. Sci. Technol. 2013, 48, 98-107. 
28. Hong, S.; Chen, W.; Zhang, Y.; Luo, H.Q.; Li, M.; Li, N.B. Investigation of the inhibition effect of trithiocyanuric acid on corrosion of copper in $3.0 \mathrm{wt} \% \mathrm{NaCl}$. Corrosion Sci. 2013, 66, 308-314.

29. Hummers, W.S.; Offeman, R.E. Preparation of graphitic oxide. J. Am. Chem. Soc. 1958, 80, 1339-1339.

30. Mhamane, D.; Ramadan, W.; Fawzy, M.; Rana, A.; Dubey, M.; Rode, C.; Lefez, B.; Hannoyer, B.; Ogale, S. From graphite oxide to highly water dispersible functionalized graphene by single step plant extract-induced deoxygenation. Green Chem. 2011, 13, 1990-1996.

31. Liang, Z.X.; Chen, W.M.; Liu, J.G.; Wang, S.L.; Zhou, Z.H.; Li, W.Z.; Sun, G.Q.; Xin, Q. FT-IR study of the microstructure of Nafion((R)) membrane. J. Membr. Sci. 2004, 233, 39-44.

32. Kopel, P.; Travnicek, Z.; Marek, J.; Korabik, M.; Mrozinski, J. Syntheses and properties of binuclear copper(II) mixed-ligand complexes involving thiodiglycolic acid. The crystal structures of $[($ phen $)(2) \mathrm{Cu}($ mu-tdga $) \mathrm{Cu}($ phen $)](\mathrm{NO} 3)(2)$ center dot $5 \mathrm{H}(2) \mathrm{O}$ and $[(\mathrm{H} 2 \mathrm{O})(\mathrm{pmdien}) \mathrm{Cu}$ (mu-tdga)Cu(pmdien)(H2O)](ClO4)(2). Polyhedron 2003, 22, 411-418.

33. Kopel, P.; Travnicek, Z.; Zboril, R.; Marek, J. Synthesis, X-ray and Mossbauer study of iron(II) complexes with trithiocyanuric acid $(\operatorname{ttcH}(3))$. The X-ray structures of $\mathrm{Fe}(\mathrm{bpy})(3)(\mathrm{ttcH})$ center dot 2 bpy center dot $7 \mathrm{H}(2) \mathrm{O}$ and $\mathrm{Fe}($ phen $)(3)(\mathrm{ttcH}(2))(\mathrm{ClO} 4)$ center dot $2 \mathrm{CH}(3) \mathrm{OH}$ center dot 2H(2)O. Polyhedron 2004, 23, 2193-2202.

34. Ranganathan, A.; Pedireddi, V.R.; Rao, C.N.R. Hydrothermal synthesis of organic channel structures: $1: 1$ hydrogen-bonded adducts of melamine with cyanuric and trithiocyanuric acids. J. Am. Chem. Soc. 1999, 121, 1752-1753.

(C) 2015 by the authors; licensee MDPI, Basel, Switzerland. This article is an open access article distributed under the terms and conditions of the Creative Commons Attribution license (http://creativecommons.org/licenses/by/4.0/). 